\title{
Pelatihan Multicam Live Streaming Kepada Siswa dan Tenaga Kependidikan Di SMKN 1 Binangun Cilacap
}

\author{
Argiyan Dwi Pritama ${ }^{1}$, Saeful Haq Faruqi ${ }^{2}$, Sharly Rizka Anizza ${ }^{3}$. \\ Universitas Amikom Purwokerto ${ }^{1,2,3}$ \\ argiyandwi@amikompurwokerto.ac.id ${ }^{1}$, ruqisaeful@gmail.com², Izzasharly9@gmail.com³.
}

Submitted: 2021--05-22 | Revised: 2021-06-11| Accepted: 2021-06-21

\begin{abstract}
When pandemic covid-19 comes out, various activities that gather the people cannot running, this means that event activities must be transferred online and broadcast through various platforms, the call it live streaming program. It can how to enjoy the show in internet on realtime. Audio and Visual that can be enjoyed without having to download the video or sound first. Therefore SMKN 1 Binangun Cilacap as an educational institution affected by the Covid-19 pandemic also needs to move and divert its online event through the live streaming. The title of this training is Multicam Live Streaming Training for Students and Education Staff at SMKN 1 Binangun Cilacap to increase the online learning, distribution information, and also school marketing in social media. This training held by presentation methode and demonstration methode will start from explaining the benefits of live streaming, preparation of live streaming both hardware and software, and technical steps to start live streaming using more than 1 image source or source. camera or what is called multicam to the live streaming platform which is this training made one program live streaming on canal Youtube SMKN 1 Binangun Cilacap.
\end{abstract}

Keywords: Live Streaming, Multicam, Platform

\begin{abstract}
Abstrak. Pada masa pandemi covid-19 seperti saat ini berbagai macam kegiatan yang melibatkan banyak orang menjadi tidak bisa di lakukan, hal ini menjadikan kegiatan acara harus dialihkan secara daring dan disiarkan secara langsung melalui berbagai macam platform atau yang kita sering sebut adalah live streaming. Streaming adalah cara untuk menikmati suara atau video yang diunggah di internet. Suara atau video yang bisa diputar dan dinikmati terus menerus, tanpa harus mengunduh video atau suaranya terlebih dahulu. Oleh karena itu SMKN 1 Binangun Cilacap sebagai lembaga pendidikan yang terdampak oleh pandemi covid-19 ini juga perlu bergerak dan mengalihkan kegiatannya secara daring yaitu melalui live streaming. Kegiatan yang bertajuk Pelatihan Multicam Live Streaming Kepada Siswa Dan Tenaga Kependidikan Di SMKN 1 Binangun Cilacap ini bertujuan untuk menunjang pembelajaran secara daring, sosialisasi, dan bahkan promosi di media sosial YouTube. Kegiatan ini dilakukan dengan metode presentasi dan demonstrasi secara langsung yaitu dimulai dari dari pemaparan kebermanfaatan live streaming, persiapan live streaming baik secara hardware
\end{abstract}


maupun software, dan langkah teknis memulai live streaming menggunakan lebih dari 1 sumber gambar atau sumber kamera atau yang disebut multicam menuju platform live streaming, dimana pelatihan ini juga menghasilkan 1 konten live streaming yang disiarlan secara langsung di kanal Youtube SMKN 1 Binangun Cilacap.

Kata Kunci: Live Streaming, Multicam, Platform

\section{Pendahuluan}

Pada masa pandemi covid19 seperti saat ini berbagai macam kegiatan yang melibatkan banyak orang menjadi tidak bisa di lakukan, hal ini menjadikan kegiatan acara harus dialihkan secara digital dan disiarkan secara langsung melalui berbagai macam platform sosial media pada khususnya atau yang kita sering sebut adalah live streaming. Ditambah lagi Saat ini kita berada pada era di mana media sosial telah menjadi bagian dari kehidupan sehari-hari masyarakat. Tidak dapat dipungkiri, kehadiran media sosial telah banyak membawa perubahan bagi kebudayaan masyarakat ${ }^{1}$. (Agustina 2018)Begitupun dengan aspek pendidikan seperti saat ini dimana kegiatan secara daring juga dimanfaatkan oleh pelaku di bidang pendidikan untuk dapat bergerak maju secara dinamis khususnya untuk menciptakan alternatif model pembelajaran seperti pembelajaran jarak jauh (distance learning). Pembelajaran jarak jauh atau merupakan metode pembelajaran dimana antara si pengajar dan yang di ajar tidak bertemu secara langsung tetapi menggunakan media-media tertentu untuk melangsungkan proses belajar mengajar. Pembelajaran jarak jauh sangat besar manfaatnya dalam penggunaan ${ }^{2}$.

Saat ini Live streaming sudah menjadi semakin popular. Berbagai platform sosial media sendiri juga mengenali hal itu dan mulai mendukung fitur ini. Twitter memiliki aplikasi streaming sendiri yang dikenal dengan nama Periscope. Facebook dan Instagram sendiri memperkenalkan fitur live di akhir tahun 2015 dan 2016. Sedangkan yang paling populer adalah live streaming pada media YouTube. YouTube Live merupakan cara mudah bagi para kreator untuk menjangkau komunitasnya secara real time. Saat menyiarkan streaming suatu acara, mengajar di kelas, atau menyelenggarakan sebuah lokakarya, YouTube memiliki alat yang akan membantu Anda mengelola livestream serta berinteraksi dengan penonton secara real time ${ }^{3}$. Livestreaming adalah konten video yang disiarkan secara langsung

1 Agustina, Lidya. 2018. "Live Video Streaming Sebagai Bentuk Perkembangan Fitur Media Sosial." Diakom: Jurnal Media Dan Komunikasi 1 (1): 17-23. https://doi.org/10.17933/diakom.v1i1.16.

2 Zahir, Abdul. 2020. "Pengembangan Media Pembelajaran Live Streaming Pengetahuan Komputer Berbasis Website.” Jurnal Ilmiah d' COMPUTARE 9 (2): 1-7.

3 Youtube.com (2021). Youtube Live Streaming. Diakses pada 7 Januari 2021, Dari https://www.youtube.com/intl/ALL_id/howyoutubeworks/product-features/live/\#youtubelive. 
melalui internet dimana tidak perlu melakukan editing dan post-production. Dikutip dari digitalponsel.com livestreaming cenderung memperoleh keterlibatan penonton hingga 10 kali lebih banyak dibanding prerecord streaming. Itu adalah pengalaman dimana pembuat video "harus hadir" saat itu. Penonton punya pilihan untuk memberikan komentar dan reaksi yang tersedia di layar secara realtime, Hal mudah untuk mengecek apakah pengguna sedang menyaksikan live streaming yakni apakah video tersebut mempunyai panjang yang ditentukan. Apabila tak ada penghujung akhir video dan pengguna pun tak bisa melompat maju , maka video itu adalah live streaming. ${ }^{4}$

Sedangkan menurut kamus bahasa Inggris Oxford mendefinisikan live streaming sebagai transmisi liputan video dan atau audio secara langsung dari suatu acara melalui internet. Mirip dengan siaran langsung yang dilakukan di televisi atau radio, perbedaannya adalah tidak perlu membayar untuk menonton pada saat membuat siaran tersebut ${ }^{5}$. (Lind 2018). Untuk memulai live streaming pada dasarnya perangkat yang digunakan adalah kamera, audio, dan encoder. Untuk encoder ini tugasnya adalah mengompresi video untuk memenuhi standar video dan streaming yang biasa dilakukan oleh perangkat lunak di PC atau laptop. Proses live streaming memang melalui tahapan yang lumayan rumit mulai dari persiapan hardware dan software, kemudian memilih platform yang dituju, namun selain itu perlu juga knowlage yang cukup agar dapat membuat acara di tayangkan secara langsung di suatu platform media. Layanan live streaming juga tersedia secara mandiri dalam sosial media seperti Periscope, Twitch, Nimo, dan lain sebaginya, atau tersedia dalam bentuk layanan khusus live video di sosial media seperti pada Facebook Live, Instagram Live, maupun TikTok Live'. (Fietkiewicz 2020).

Pendekatan kegiatan secara daring ini pada beberapa aspek pendidikan sudah banyak diterapkan karena memang tuntutan keadaan dan juga tuntutan kebutuhan kepada siswa atau pelaku pendidikan yang lebih beragam, seperti halnya pada pengabdian yang dilakukan oleh Suheri dengan judul "Sosialisasi Penggunaan Aplikasi Zoom Meeting Dan Google Classroom Pada Guru Di Sdn 17 Mata Air Padang Selatan" yang berfokus penggunaan media Zoom dan Classroom pada penerapan pembelajaran daringnya (Sobron, Titik, and Meidawati 2020) ${ }^{7}$. Begitupun pelatihan yang dilakukan oleh Erniwati dengan judul "Edukasi dan Pelatihan Terbimbing Bagi Guru Mengenai Pembelajaran

${ }^{4}$ Digitalponsel.com. (2020). Arti Streaming Video. Diakses pada 7 Januari 2021, Dari https://www.digitalponsel.com/25257/arti-streaming-video/

${ }^{5}$ Lind, Joonas. 2018. "The Role and Potential of Live Streaming in Marketing for Small and Medium-Sized Enterprises," 33.

${ }^{6}$ Fietkiewicz, Kaja J. 2020. The Law of Live Streaming: A Systematic Literature Review and Analysis of German Legal Framework. Lecture Notes in Computer Science (Including Subseries Lecture Notes in Artificial Intelligence and Lecture Notes in Bioinformatics). Vol. 12194 LNCS. Springer International Publishing. https://doi.org/10.1007/978-3-030-49570-1_16.

${ }^{7}$ Sobron, Adi Nugraha, Sudiatmi Titik, and Suswandari Meidawati. 2020. "Jurnal Inovasi Penelitian.” Jurnal Inovasi Penelitian 1 (3): 1-4. 
Secara Daring Sebagai Upaya Pencegahan Covid-19" yang sama menitikberatkan pada proses pembelajaran daring sebagai upaya pencegahan virus (Erniwati, Anas, and Hunaidah 2021) ${ }^{8}$

Lain halnya dengan pelatihan yang dilakukan oleh Dessy yang berjudul "Bimbingan Teknis Pembelajaran Daring Menggunakan Aplikasi Quizizz Bagi Guru Sekolah Dasar Pada Masa Pandemi Covid-19” kepada Guru, dimana pelatihan nya berfokus pada metode kuis menggunakan aplikasi Quizizz yang akan merangsang pengetahuan siswa terhadap materi tertentu (Sari and Rini 2020) $)^{9}$. Sepertihalnya pelatihan yang dilakukan Dessy diatas, pada "Pelatihan Dan Pendampingan Pengaplikasian Media Pembelajaran Daring Bagi GuruGuru Bahasa Indonesia Jenjang SMA/SMK Se-Kecamatan Buleleng” yang dilakukan oleh Ida Ayu Made Darmayanti kepada Guru-guru Bahasa Indonesia de Kecamatan Buleleng juga berfokus pada satu model pembelajaran daring menggunakan model Schoology (Darmayanti and Sutama 2019) ${ }^{10}$. Dari literaturliteratur pelatihan diatas pelatihan penulis memberikan pembaharuan dan perluasan manfaat melalui livestreaming yang selain untuk menunjang proses pembelajaran secara daring juga dapat digunakan untuk menyampaikan informasi, sosialisasi, dan bahkan promosi secara daring secara realtime dengan kualitas tayangan yang maksimal.

Oleh karena itu SMKN 1 Binangun Cilacap sebagai lembaga pendidikan yang terdampak juga oleh pandemi covid19 ini juga perlu bergerak dan mengalihkan kegiatannya secara daring yaitu melalui live streaming. Apalagi SMKN 1 Binangun Cilacap sudah memiliki jurusan Multimedia dan memiliki sumberdaya alat yang cukup. Dengan melakukan live streaming SMKN 1 Binangun Cilacap juga bisa menyelenggarakan kembali kegiatan pendidikannya yang sempat terhambat, misalnya acara-acara di sekolah. Selain itu SMKN 1 Binangun Cilacap juga bisa menjangkau audience baru di luar sekolah yang mungkin tidak bisa dilakukan dengan cara marketing tradisional.

Pada permasalahan yang di alami oleh objek pengabdian ini yaitu SMKN 1 Binangun Cilacap adalah Sumber daya manusia yang belum maksimal dalam pemahaman secara teknis mengenai proses, alur, dan setup live streaming. Oleh karena itu tim dosen Universitas Amikom Purwokerto memberikan Pelatihan Multicam Live Streaming Kepada Siswa Dan Tenaga Kependidikan Di

${ }^{8}$ Erniwati, Muhammad Anas, and Hunaidah. 2021. "Edukasi Dan Pelatihan Terbimbing Bagi Guru Mengenai Pembelajaran Secara Daring Sebagai Upaya Pencegahan Covid-19.” Jurnal ABDINUS : Jurnal Pengabdian Nusantara 4 (2): 458-69.

9 Sari, D D, and T P W Rini. 2020. "Bimbingan Teknis Pembelajaran Daring Menggunakan Aplikasi Quizizz Bagi Guru Sekolah Dasar Pada Masa Pandemi Covid-19." $\begin{array}{lllll}\text { Jurnal Pendidikan Dan } & \text { Pengabdian } & \ldots & 3\end{array}$ http://www.jurnalfkip.unram.ac.id/index.php/JPPM/article/view/2204.

10 Darmayanti, I A M, and I M Sutama. 2019. "Pelatihan Dan Pendampingan Pengaplikasian Media Pembelajaran Daring Bagi Guru-Guru Bahasa Indonesia Jenjang Sma/Smk Se ...” Pendidikan, 1019-27. https://eproceeding.undiksha.ac.id/index.php/senadimas/article/download/1856/1260. 
SMKN 1 Binangun Cilacap sehingga acara di sekolah yang sempat terhenti akibat pandemi covid19 dapat berjalan kembali serta dapat memanfaatkan penggunaan live streaming untuk memberikan edukasi, menjalin komunikasi, serta mengembangkan bakat para siswa dan tenaga kependidikan SMKN 1 Binangun Cilacap.

\section{Hasil dan Pembahasan}

Metode yang digunakan pada pengabdian ini adalah metode presentasi dan demonstrasi kepada siswa dan tenaga kependidikan di SMKN 1 Binangun Cilacap. Untuk siswa akan di khususkan pada siswa di jurusan multimedia SMKN 1 Binangun Cilacap, tujuannya adalah agar jurusan multimedia SMKN 1 Binangun Cilacap semakin berkembang keilmuannya.

Pelaksanaan kegiatan pada sesi presentasi untuk memaparkan materi yang akan di praktikan, materi yang pertama adalah mempersiapkan perangkat lunaknya untuk kebutuhan audio dan visual, selanjutnya setup live streaming nya mulai dari alur instalasi hardware untuk kebutuhan live, alur perkabelan audio dan video, hingga penggunaan capture card untuk memproses kamera agar gambar dari hasil kamera dapat terbaca di komputer utama. Pada dasarnya hampir semua kamera bisa digunakan untuk kebutuhan live streaming atau live broadcasting dengan syarat ada port output di kamera sebagai luaran dari gambar kamera, kecuali kamera tipe webcam yang bisa langsung terdeteksi oleh ke laptop komputer ketika dikoneksikan.

\section{- Kamera Broadcasting}
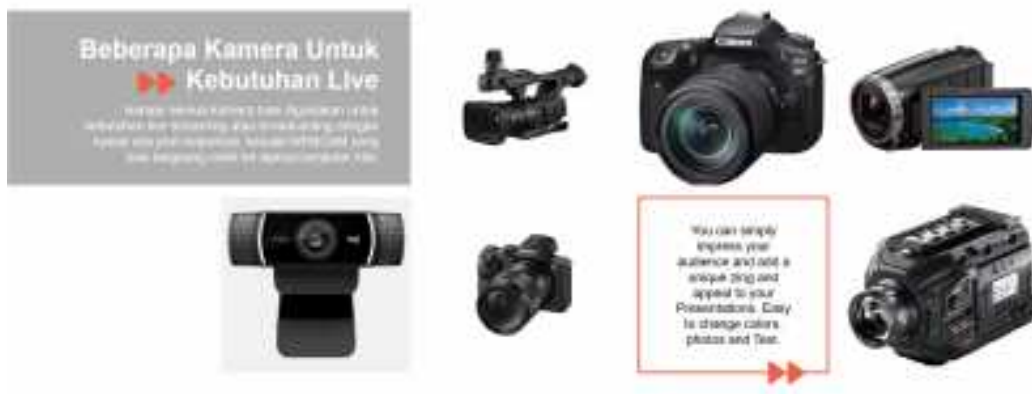

Gambar 1. Materi Peralatan kamera Yang Bisa Digunakan

Selanjutnya materi mengenai siaran langsung menggunakan multicam atau lebih dari dua kamera untuk keperluan live streaming yang banyak digunakan pada seminar online atau webinar yang merupakan sarana efektif untuk melakukan seminar dengan penonton yang tersebar di berbagai tempat tanpa perlu menyewa ruangan. Streaming Ibadah sekarang juga menjadi opsi bagi rumah ibadah yang ingin menayangkan ibadah untuk jemaat yang berhalangan hadir. Para pengguna YouTube atau yang disebut Youtuber juga seringkali melakukan 
kegiatan ini untuk membuat konten dan juga bisa berkomunikasi ke fans dan follower secara live.

Pada SMKN 1 Binangun Cilacap ini sendiri dari observasi yang sudah penulis lakukan, program live streaming ini akan digunakan pada kegiatan acaraacara sekolah, baik webinar hingga pembelajaran daring untuk siswa dari guru matapelajaran, sehigga diharapkan kegiatan pelatihan ini akan sangat membantu kedepannya.

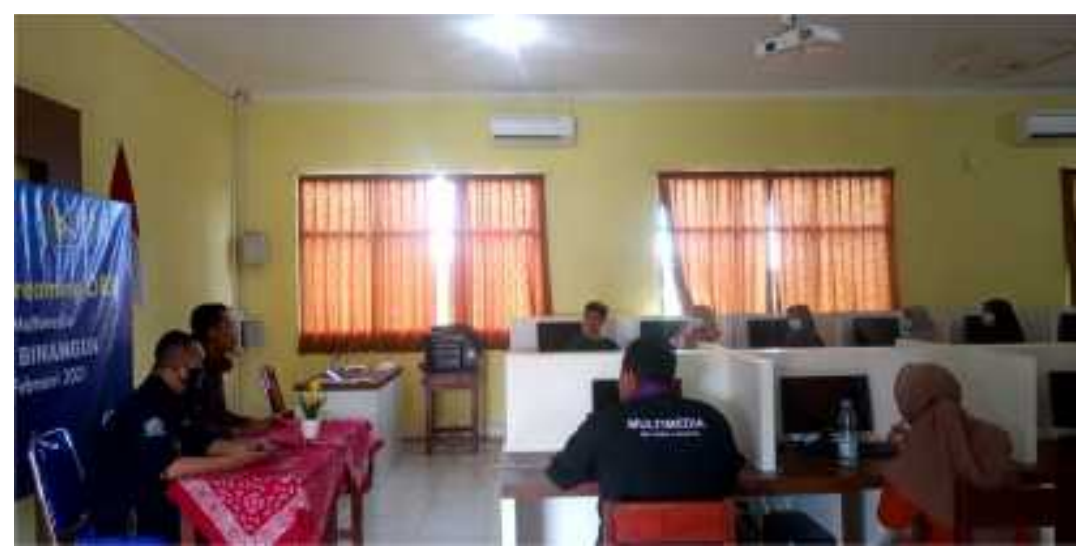

Gambar 2. Presentasi dan Pemaparan Materi Multicam Live Streaming Kepada Siswa Dan Tenaga Kependidikan Di Smkn 1 Binangun Cilacap

Materi selanjutnya dalam pelatihan ini perangkat lunak yang digunakan adalah Open Broadcaster Software (OBS) yang merupakan program streaming dan rekaman cross-platform gratis dan open source. Dengan capture card, kamera dan OBS acara apapun bisa di live streamingkan dengan kualitas yang baik. Di OBS kita juga bisa masukan input slide presentasi, logo, dan lain lain agar acara yang ditayangkan secara langsung lebih menarik. Perangkat lunak ini yang nanti akan menjadi materi yang berikan untuk penggunaannya.

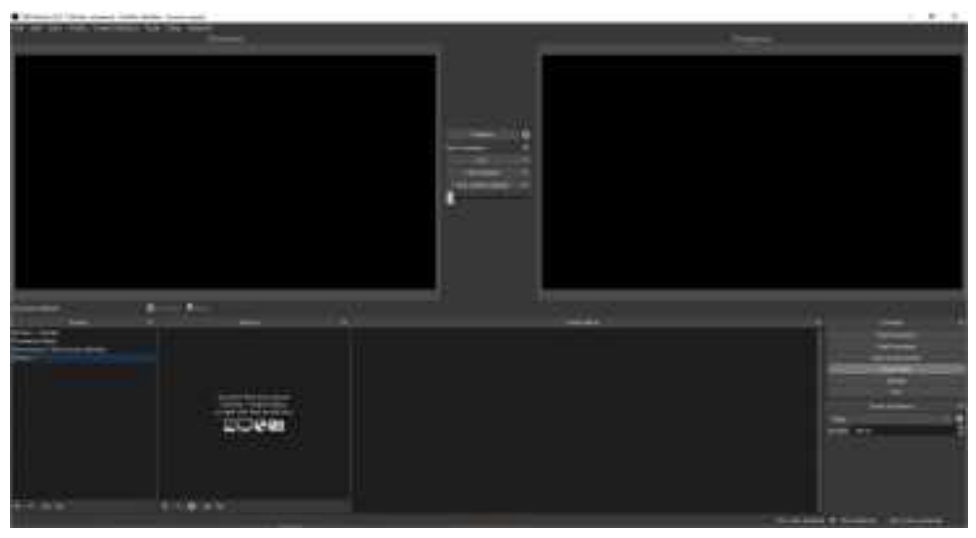

Gambar 3. Software Live Streaming Open Broadcaster Software (OBS) 
Selanjutnya pelaksanaan kegiatan pada tahap masuk pada tahap demonstrasi, mulai praktik dan transfer knowladge dengan para siswa dan tenaga kependidikan. Pada proses praktik demonstrasi secara langsung ini di mulai dari cara alur instalasi hardware untuk kebutuhan live, alur perkabelan baik audio dan video atau kameranya, serta penggunaan capture card untuk memproses kamera agar gambar dapat terbaca di perangkat lunak live streaming yang digunakan yaitu OBS.

Proses persiapan untuk live streaming dimulai dari pengecekan segala perangkat keras yang diperlukan seperti kamera, komputer, audio sistem, HDMI kabel dan properti yang diperlukan. Pada tahap ini juga peserta pelatihan dibagi beberapa tim untuk mempersiapkan konten yang akan disampaikan pada acara yang disiarkan secara live.

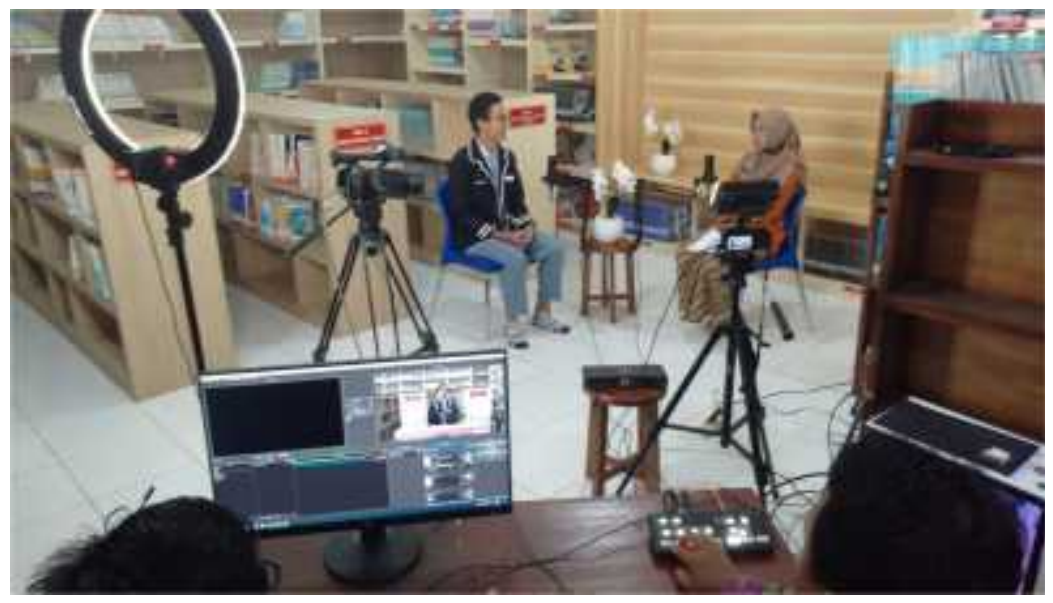

Gambar 4. Persiapan Acara Live Streaming SMKN 1 Binangun Cilacap

Kegiatan pelatihan ini pada akhirnya akan menghasilkan konten live streaming untuk SMKN 1 Binangun Cilacap, sehingga peserta disiapkan sekaligus menjadi tim pelaksanaan acara SMKN 1 Binangun Cilacap yang di siarkan di kanal You'Tube SMKN 1 Binangun.

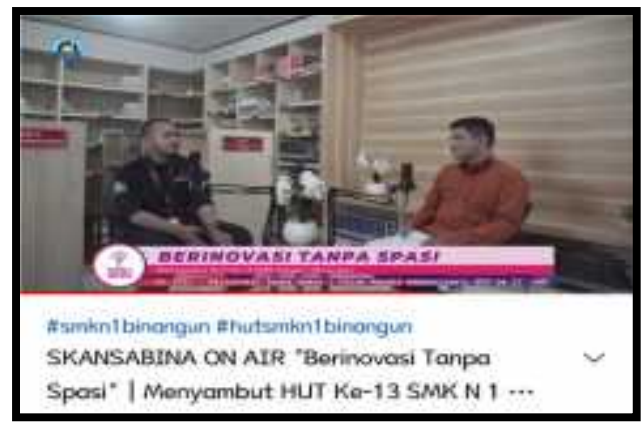

Gambar 5. Live Event SKANSABINA ON AIR "Berinovasi Tanpa Spasi" | Menyambut HUT Ke-13 SMK N 1 Binangun 


\section{Penutup}

Dengan pelatihan ini SMKN 1 Binangun Cilacap sudah siap untuk mengalihkan segala kegiatan yang sudah direncanakan dan disusun melalui daring, selain itu SMK juga bisa menghasilkan acaranya sendiri dan disiarkan secara langsung di kanal YouTube SMKN 1 Binangun Cilacap dengan menggunakan teknik multi kamera atau multicam, acara yang dihasilkan dari pelatihan ini bertajuk Skansabina On Air "Berinovasi Tanpa Spasi" yang selanjutnya disiarkan secara live melalui youtube.

Acara ini juga telah dapat memenuhi aspek promosi sekolah kepada khalayak ramai melalui sosial media yang sedang ramai yaitu YouTube dan dapat digunakan secara berkelanjutan dengan mengangkat tema-tema pembahasan yang berbeda.

\section{Daftar Pustaka}

Agustina, Lidya. 2018. "Live Video Streaming Sebagai Bentuk Perkembangan Fitur Media Sosial." Diakom: Jurnal Media Dan Komunikasi 1 (1): 17-23. https://doi.org/10.17933/diakom.v1i1.16.

Darmayanti, I A M, and I M Sutama. 2019. "Pelatihan Dan Pendampingan

Pengaplikasian Media Pembelajaran Daring Bagi Guru-Guru Bahasa Indonesia Jenjang Sma/Smk Se ...." Pendidikan, 1019-27. https:/ / eproceeding.undiksha.ac.id/index.php/senadimas/article/downlo ad/1856/1260.

Erniwati, Muhammad Anas, and Hunaidah. 2021. "Edukasi Dan Pelatihan Terbimbing Bagi Guru Mengenai Pembelajaran Secara Daring Sebagai Upaya Pencegahan Covid-19." Jurnal ABDINUS: Jurnal Pengabdian Nusantara 4 (2): 458-69.

Fietkiewicz, Kaja J. 2020. The Law of Live Streaming: A Systematic Literature Review and Analysis of German Legal Framework. Lecture Notes in Computer Science Including Subseries Lecture Notes in Artificial Intelligence and Lecture Notes in Bioinformatics). Vol. 12194 LNCS. Springer International Publishing. https://doi.org/10.1007/978-3-030-49570-1_16.

Lind, Joonas. 2018. "The Role and Potential of Live Streaming in Marketing for Small and Medium-Sized Enterprises," 33.

Sari, D D, and T P W Rini. 2020. "Bimbingan Teknis Pembelajaran Daring Menggunakan Aplikasi Quizizz Bagi Guru Sekolah Dasar Pada Masa Pandemi Covid-19." Jurnal Pendidikan Dan Pengabdian ... 3 (4). http://www.jurnalfkip.unram.ac.id/index.php/JPPM/article/view/2204.

Sobron, Adi Nugraha, Sudiatmi Titik, and Suswandari Meidawati. 2020. "Jurnal Inovasi Penelitian." Jurnal Inovasi Penelitian 1 (3): 1-4. 